\title{
Functional Impairments and Work-Related Outcomes in Breast Cancer Survivors: A Systematic Review
}

\author{
Rimke Bijker ${ }^{1}$ (D) Saskia F. A. Duijts ${ }^{2,3} \cdot$ Sherzel N. Smith $^{1} \cdot$ Renée de Wildt-Liesveld ${ }^{1}$. Johannes R. Anema ${ }^{3,4}$. \\ Barbara J. Regeer ${ }^{1}$
}

Published online: 30 October 2017

(c) The Author(s) 2018. This article is an open access publication

\begin{abstract}
Purpose Work participation after breast cancer treatment is generally negatively affected. Occupational health professionals might improve work-related outcomes by bridging the gap between sick-listed employees' levels of functioning and work demands. To aid them in this task, this review explored the association between functional impairments and work-related outcomes in breast cancer survivors. Methods Publications from January 2000-March 2016 were identified through five online databases (i.e. Pubmed, EMBASE, PsycINFO, CINAHL and the Cochrane Library). Quantitative and qualitative studies were included if they focused on functional impairments and work-related outcomes in breast cancer survivors. Two reviewers independently selected studies, extracted data and performed quality assessment. Results The search identified 998 studies, of which 20 studies met eligibility criteria. Impairments in physical functioning negatively affected return to work (RTW) and work ability in quantitative and qualitative studies. Studies measuring cognitive functioning with tests found no association with work-related outcomes, whereas the results of studies using self-reported measures were ambiguous. Social functioning was less commonly investigated and findings differed across work-related outcomes. Emotional functioning was not associated with work-related outcomes in quantitative studies, while in qualitative studies feelings such as insecurity were described as influencing RTW. Conclusions Functional impairments can severely hamper work participation in breast cancer survivors. This provides important opportunities for occupational health professionals to enhance RTW in breast cancer survivors, such as adequately addressing illness perceptions and work expectations. Ongoing research is warranted to aid occupational health professionals in providing effective vocational guidance and improve work-related outcomes in breast cancer survivors.
\end{abstract}

Keywords Breast cancer $\cdot$ Functional impairments $\cdot$ Return to work $\cdot$ Occupational health services

\section{Introduction}

Rimke Bijker

rbijker@kirby.unsw.edu.au

Saskia F. A. Duijts

s.duijts@vumc.nl

1 Athena Institute, VU University Amsterdam, Amsterdam, The Netherlands

2 Division of Psychosocial Research and Epidemiology, The Netherlands Cancer Institute, Amsterdam, The Netherlands

3 Department of Public and Occupational Health, VU University Medical Center, Van der Boechorststraat 7 C573, 1081 BT Amsterdam, The Netherlands

4 Research Center for Insurance Medicine, AMC-UMCG-UWV-VUmc, Amsterdam, The Netherlands
The incidence of breast cancer is increasing globally [1], and although early diagnosis and better treatment options have improved survival, participation in society after breast cancer is generally negatively affected [2]. Many women are not able to return to work (RTW) or experience diminished work outcomes, such as increases in sick leave and lowered work ability [2-4]. This puts an economic burden on society, since about $70 \%$ of new breast cancer cases occur in women of working age [5]. Moreover, being able to work is of great importance on an individual level as well, as work contributes to a sense of normalcy [6], financial security [7-9], and improved quality of life $[10,11]$.

Evidence from systematic reviews related to cancer and work reveals that factors associated with RTW in cancer 
survivors include, among others, age, socio-economic status, disease stage, type of treatment and treatment-related symptoms [12, 13]. In addition, it has been suggested that successful RTW is influenced by the extent to which the cancer survivor's level of functioning meets the demands at work [14]. For example, breast cancer surgery is associated with lymphedema [15], which in turn can impair arm function [16] and consequently may affect specific physical tasks in different work environments. Also, chemotherapy and its related side effects may induce cognitive impairment [17, 18], which may influence the ability to concentrate while at work. As such, successful RTW might be enhanced by interventions that include vocational support, to help overcome the discrepancy between the level of functioning of breast cancer survivors and the demands of work.

The potential of vocational support is further emphasized in a recent meta-analysis that summarized the effects of various RTW interventions in cancer survivors [19]. Among the evaluated interventions were monodisciplinary interventions (including physical, psycho-educational and medical interventions) and multidisciplinary interventions (interventions that combined aspects of monodisciplinary interventions with vocational components). None of the monodisciplinary interventions showed a beneficial effect on RTW. By contrast, moderate quality evidence was found that RTW was positively influenced by multidisciplinary interventions which combined physical and psycho-educational components with vocational components. These findings underline the importance of providing vocational guidance and occupational health services for those who are returning to work.

As in several other high-income countries, in the Netherlands, employers are required to offer occupational health services [20]. These services are generally provided by occupational health professionals. Part of their responsibilities includes the facilitation of vocational rehabilitation. Internationally, occupational health professionals are required to have a profound base of general medical knowledge and to be commonly familiar with the workplace and work tasks $[21,22]$. Therefore, they are in an ideal position to provide vocational guidance. More specifically, they can aid sicklisted employees by helping them increase their level of functioning to meet work demands, or by adjusting the work environment so that employees can work despite functional impairments.

To offer proper vocational guidance, it is necessary that occupational health professionals have knowledge regarding the relation between the level of functioning of sicklisted employees and the ability to resume work. To our knowledge, this relationship with respect to breast cancer survivors has not previously been addressed by systematic reviews. Yet, providing an overview of this topic is especially relevant as the growing number of working age breast cancer survivors implies that these women will constitute an increasing proportion of the occupational health professionals' tasks. Therefore, the aim of this review was to explore the association between functional impairments and workrelated outcomes in breast cancer survivors.

\section{Methods}

\section{Search Strategy}

A systematic search was performed in the databases PubMed, EMBASE, PsycINFO, CINAHL and in the Cochrane Library, restricted to studies published from January 2000 until March 2016. Studies were identified using search syntaxes based on the PubMed strategy, which uses a combination of MeSH terms and free text terms that were related to breast cancer, functional impairments and employment. Subsequently, the search syntax was adapted per database, including different or additional search terms where necessary (Appendices 1, 2, 3, 4 and 5). Functional impairment was defined as limitations due to a condition or its treatment that prevent people from carrying out certain functions in their daily life. Breast cancer survivor refers to women who have been diagnosed with breast cancer, regardless of breast cancer stage, time since diagnosis and type of treatment. Studies published in English were eligible for inclusion if they evaluated functional impairments in relation to workrelated outcomes in breast cancer survivors with an employment contract at time of diagnosis. Both original quantitative and qualitative studies of which the study populations comprised working age adults were included. Studies were excluded if the majority of the study population had a condition or cancer type other than breast cancer, if there was no mention of functional impairments (for instance if only symptoms were evaluated) or if the work-related outcomes were focused on economic consequences only, such as a loss of income.

\section{Study Selection}

Study selection was performed in three steps. First, the search results were screened by title and abstract. Second, full-text articles were retrieved to assess if they met the inclusion criteria. Third, a manual search of reference lists of included articles was conducted to identify further relevant studies. The first two steps were independently performed by two authors (RB and SS). In case there was no consensus regarding the eligibility of the articles, a third author (SD) decided if the article should be included in the review. For articles that were excluded, reasons for not including them are documented in Fig. 1. 
Fig. 1 Study selection

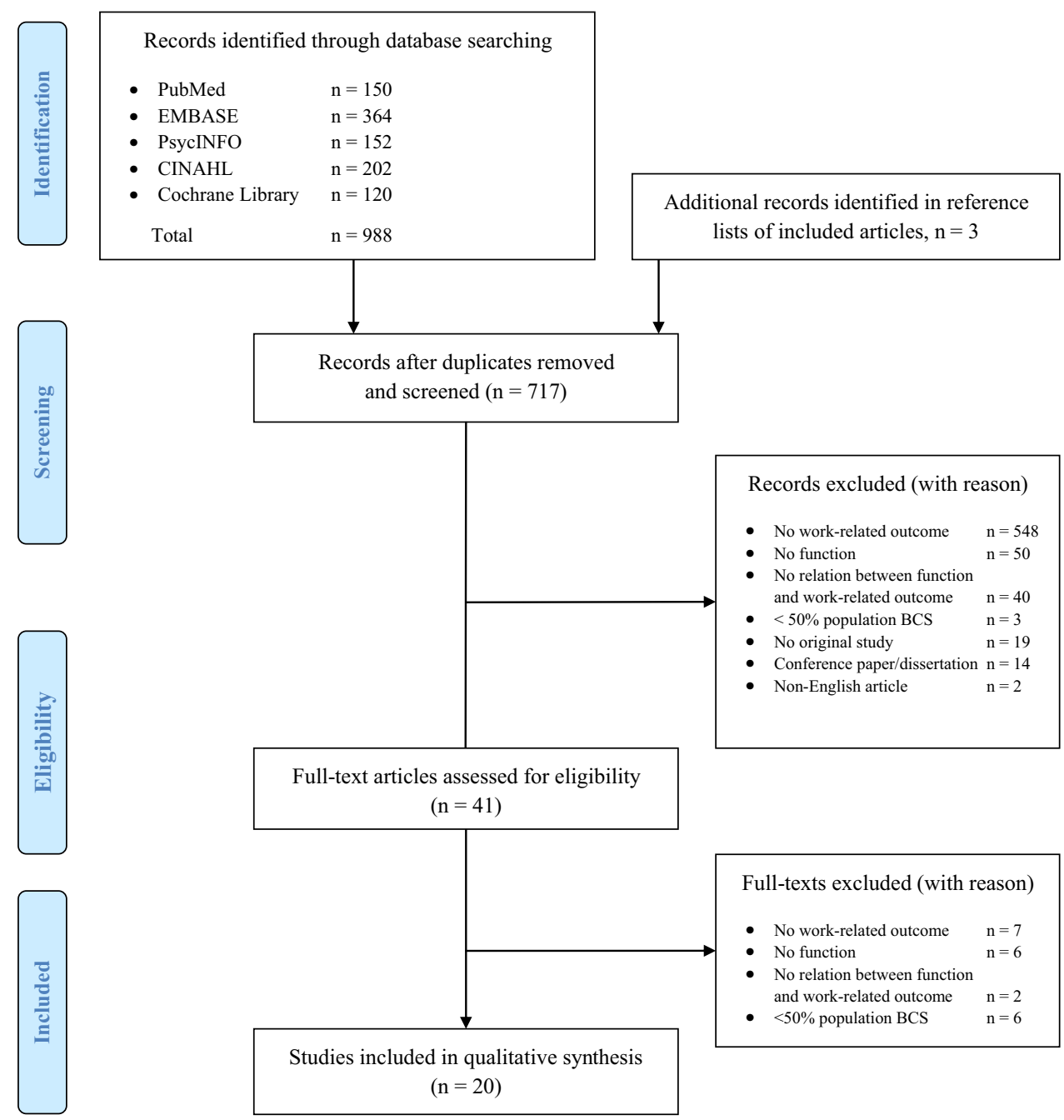

\section{Data Extraction and Synthesis}

A data extraction form was created to record relevant study details. One author (RB) extracted data on country, study design, population (e.g., number of participants, age, breast cancer stage and received breast cancer treatment), measures of functional impairments (e.g., physical, cognitive, social functioning), work-related outcomes (e.g., sick leave, return to work, work performance and work retention) and main findings of the study. We derived our measures of functional impairments from the European Organization for Research and Treatment of Cancer Quality of Life Questionnaire (EORTC QLQ) since this tool has been widely used in cancer research. We carefully assessed the EORTC QLQ and decided to use its scales regarding functioning as predefined categories to extract and group information on functional impairments. To adequately reflect the findings grouped under each category we later defined the categories as general and role functioning (i.e. overall functioning and the ability to perform common tasks at home and work), physical functioning (i.e. physical ability in general, physical work ability and shoulder functioning), cognitive functioning (i.e. cognitive ability in general, mental work ability, memory, concentration, focusing, processing, executive functioning and multitasking), social functioning (i.e. pursuing social activities), and emotional functioning (i.e. emotional functioning in general, emotional response to condition and ability to deal with stress). The extracted data were checked by another author (SS) and in cases of disagreement, a third author (SD) decided which data needed to be reported. Subsequently, the study characteristics and the results of the included studies were summarized by functional impairment and grouped according to work-related outcome if applicable.

\section{Quality Assessment}

The methodological quality of the studies was scored independently by two authors (RB, RWL), using quality assessment checklist for prognostic studies, case-control studies 
and qualitative studies that were derived from the Critical Appraisal Skills Program (CASP) [23] and for cross-sectional studies we used checklists derived from the Strengthening the Reporting of Observational Studies in Epidemiology (STROBE) [24]. Each of these checklists contains items related to the clarity of the research objective, appropriateness of the research design, appropriateness of the sampling strategy, description of the method of analysis, and clarity of the data description. Inconsistencies in scoring were discussed until agreement was reached by two researchers (RB, RWL). In case studies did not score positively on each of the items on the checklists, we described in what aspect (i.e. on which items) they were lacking quality.

\section{Results}

\section{Study Characteristics}

In total, 998 studies were identified from the systematic search and three additional relevant studies were found in the manual reference list search of included articles. After removing duplicates, and exclusion based on title and abstract, 41 full-text articles were retrieved for full-text screening. Of these, 21 studies were excluded because they did not meet the selection criteria (Fig. 1). An overview of the main characteristics of the remaining 20 studies and their findings is provided in Tables 1 and 2. In short, 11 studies had a quantitative design [25-35] and nine had a qualitative design [7, 36-43]. The majority of the studies was conducted in the United States $(n=7)$ [26, 27, 30, 33, 36, 38, 43] and Europe (Netherlands, $\mathrm{n}=3$ [25, 37, 41]; United Kingdom, $\mathrm{n}=3$ [7, 28, 39]; Sweden, $\mathrm{n}=3$ [31, 32, 40]; joint cohort Nordic countries, $n=1$ [29]), two studies were conducted in Canada [34, 35] and one in Malaysia [42]. Seven studies were of prospective nature, with follow-up periods ranging from 3 months to 4 years $[25,28,31-34]$ and 13 studies had a cross-sectional design [7, 26, 27, 29, 30, 35-43]. One study was reported in two articles, with the first comprising the baseline results [35] and the other reporting the findings at long-term follow-up [34]. Four studies reported on shortterm outcomes, occurring in the first year after breast cancer diagnosis [28, 31, 35, 40], while 14 studies reported on long-term outcomes [7, 25-27, 29, 30, 32-34, 36, 38, 39, 41, 43]. Two qualitative studies did not clearly define how much time had elapsed between breast cancer diagnosis and the problems participants disclosed [37, 42]. Study sample sizes ranged from $n=44$ to $n=1111$ breast cancer survivors in the quantitative studies and from $n=10$ to $n=74$ survivors in the qualitative studies. None of the studies included male breast cancer survivors in their study sample. In two studies, the populations consisted of a mixed cancer group, in which seven out of ten participants (70\%) [37] and 219 out of 431 participants (51\%) [29] were treated for breast cancer. In only two studies, the results regarding the relation between impairment of functioning and work were compared to a control group $[26,30]$.

\section{Quality Assessment}

Overall, we agreed that the methodological quality of the studies was high. For 11 studies, all items in the quality assessment were scored positively [27-32, 34, 37, 40, 41, 43]. In the remaining articles reporting on quantitative studies there may have been confounding [33], some measurement bias [25], or there was a lack of clarity regarding participant sampling $[26,35]$. In one article there was also insufficient discussion of potential bias, generalizability and the interpretation of the results [35]. Concerns about articles reporting on qualitative studies were mainly related to adequately addressing ethical issues $[7,36,38]$ and considering the relationship between researcher and participants $[7$, 38, 39, 42]. Furthermore, one of these articles also scored negatively on the appropriateness of the research design and the method of data analysis [38]. Taking into consideration the assessed quality of the studies, we decided not to deploy a weight difference when describing the results.

\section{Quantitative Studies}

A total of 11 studies reported quantitative results regarding one or more domains of functioning [25-35]. Three studies described general functioning [27, 28, 31], seven studies described physical functioning [25, 28, 29, 31, 33-35], six studies described cognitive functioning [26, 28-31, 33], two studies described social functioning in general [28, 31], and finally, three studies described emotional functioning in general [28, 31,32]. These domains were evaluated by means of medical assessment [25, 34, 35], telephone interviews [33], neuropsychological performance tests [26], or questionnaires, such as the Cognitive Symptom Checklist [26, 30], Activity Level Scale [27], Work Ability Index (which covers physical and cognitive work ability) [29], Cognitive Stability Index [31], or EORTC QLQ-C30 [28, 32] and Breast Cancer-Specific Quality of Life Questionnaire (QLQ-BR23) $[31,32]$. The domains of functioning were investigated in relation to work ability [26, 27, 29, 30, 34, 35], RTW [28, 31], duration until RTW [25, 28], employment status [29, $33]$, sickness absence [27, 32] and working hours [33].

\section{General and Role Functioning}

Functional status in general and role functioning were investigated in relation to various work-related outcomes. The findings indicated that better functional status was associated with less sickness absence, and higher work productivity 


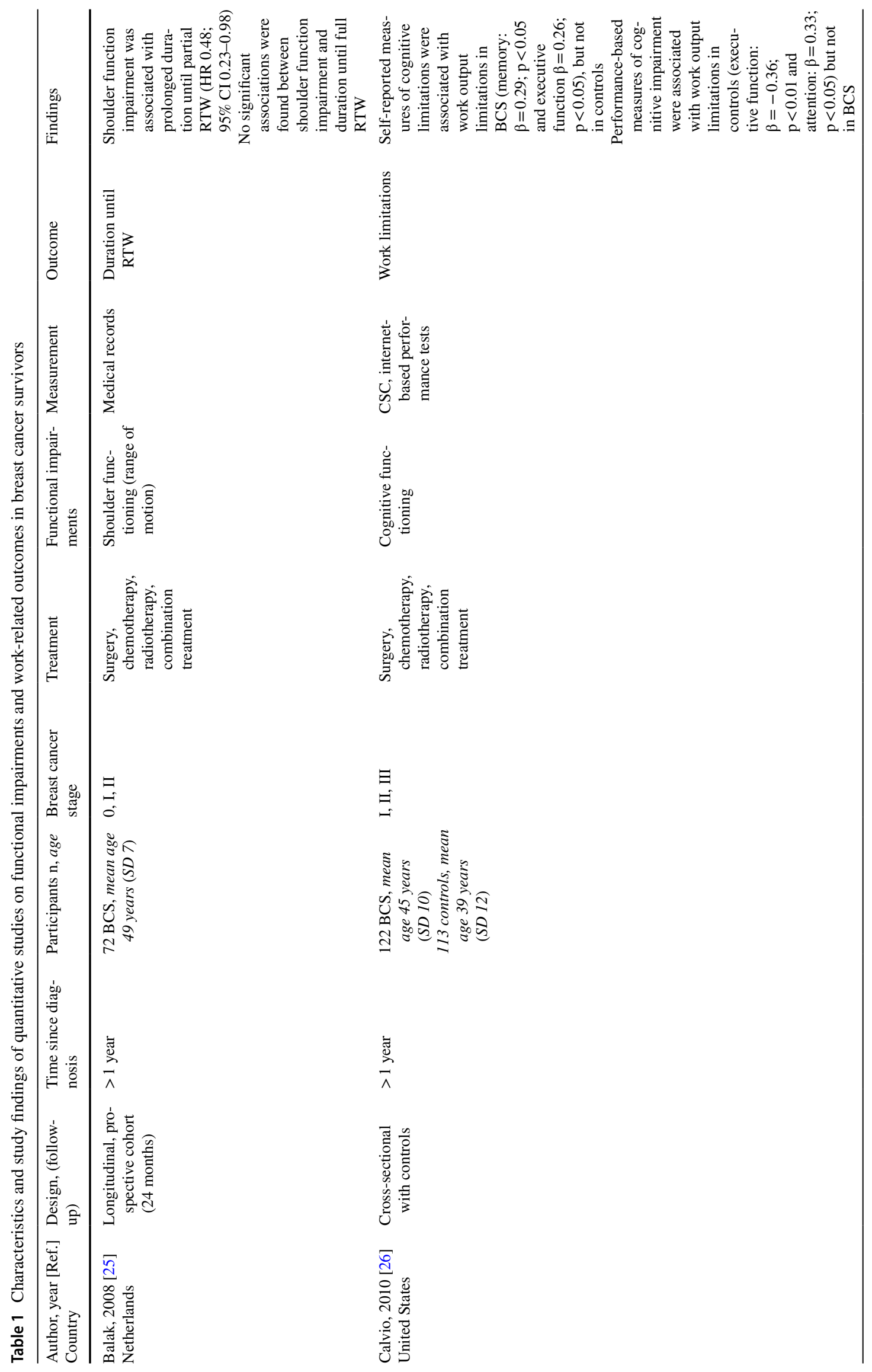




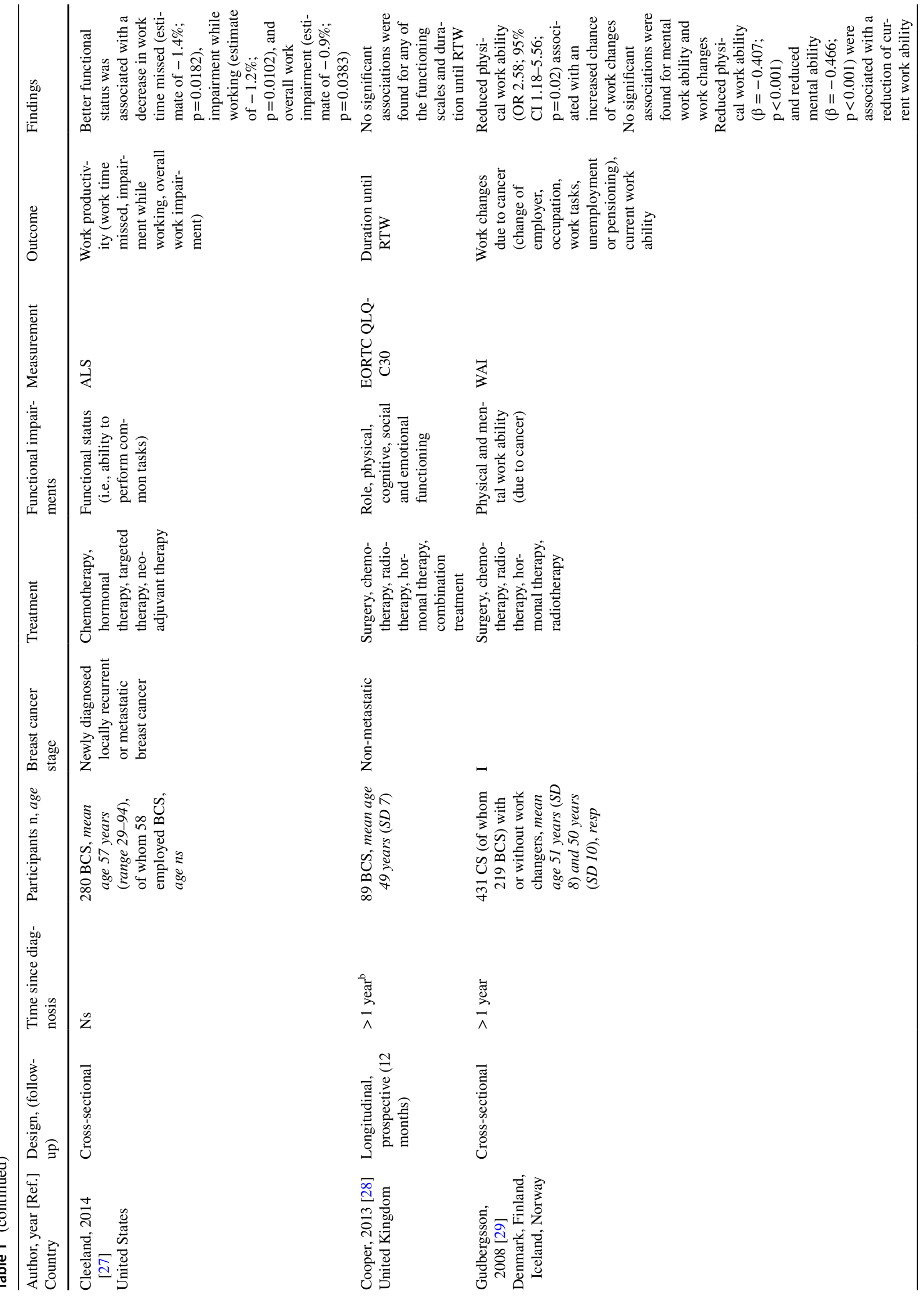




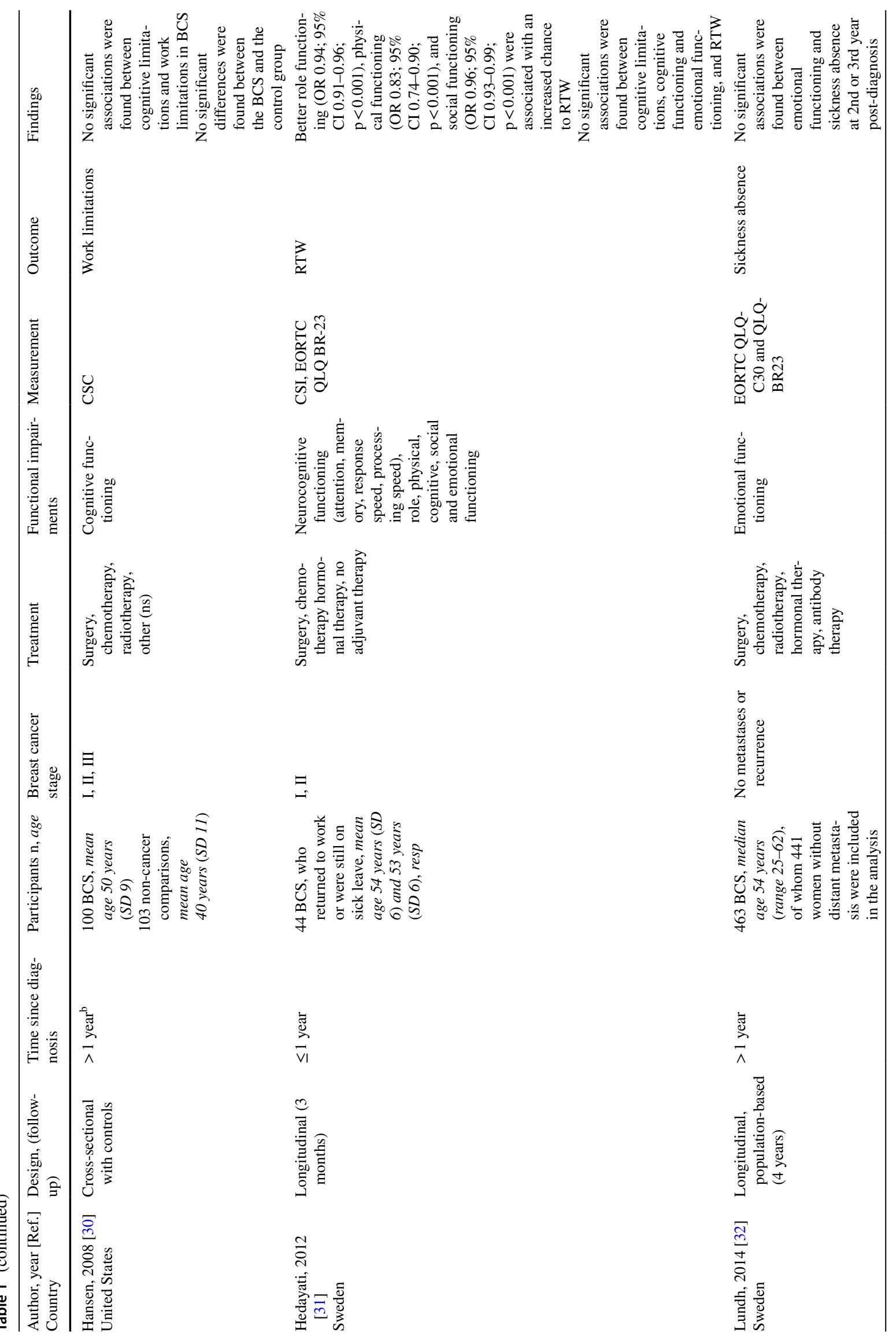




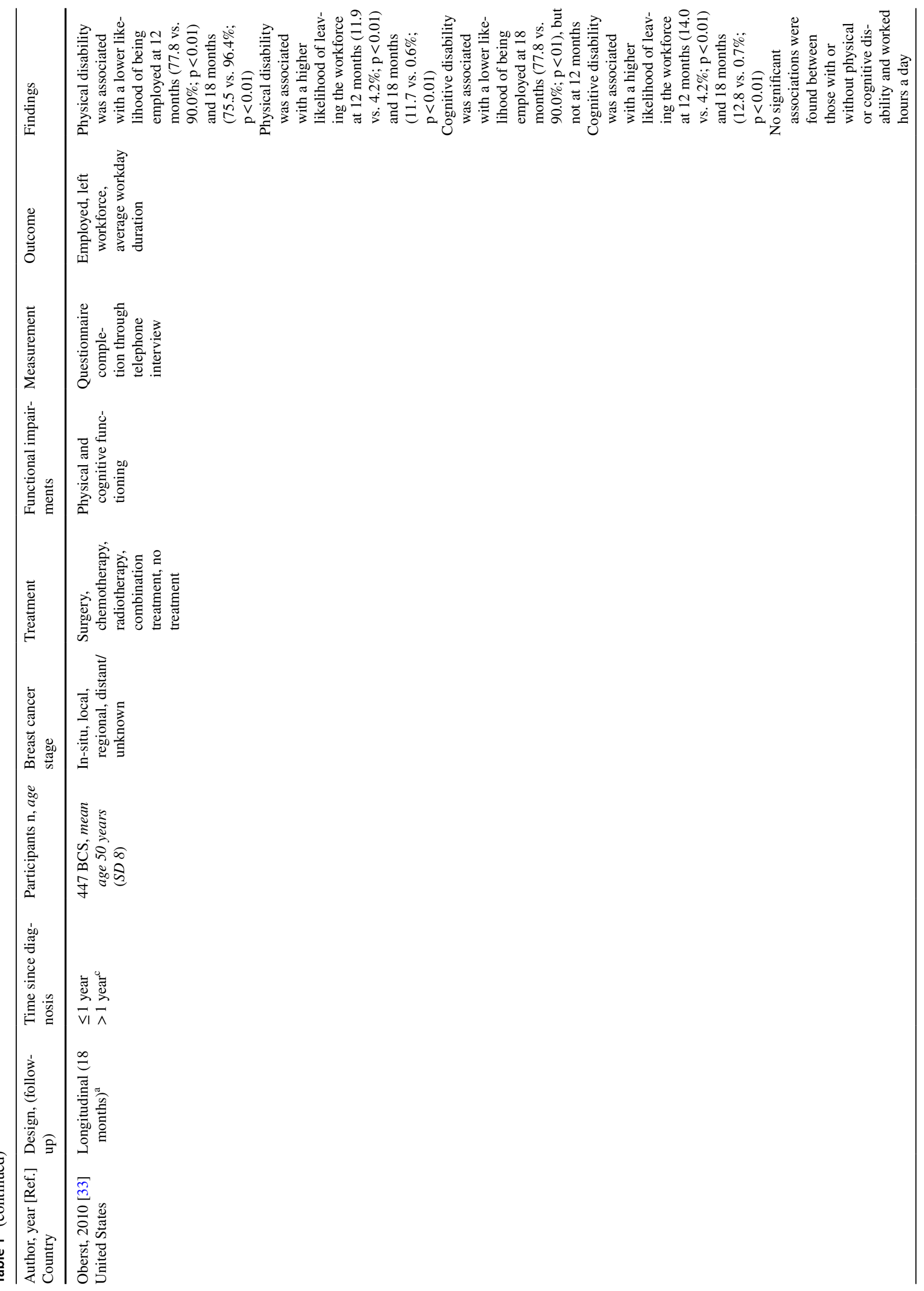




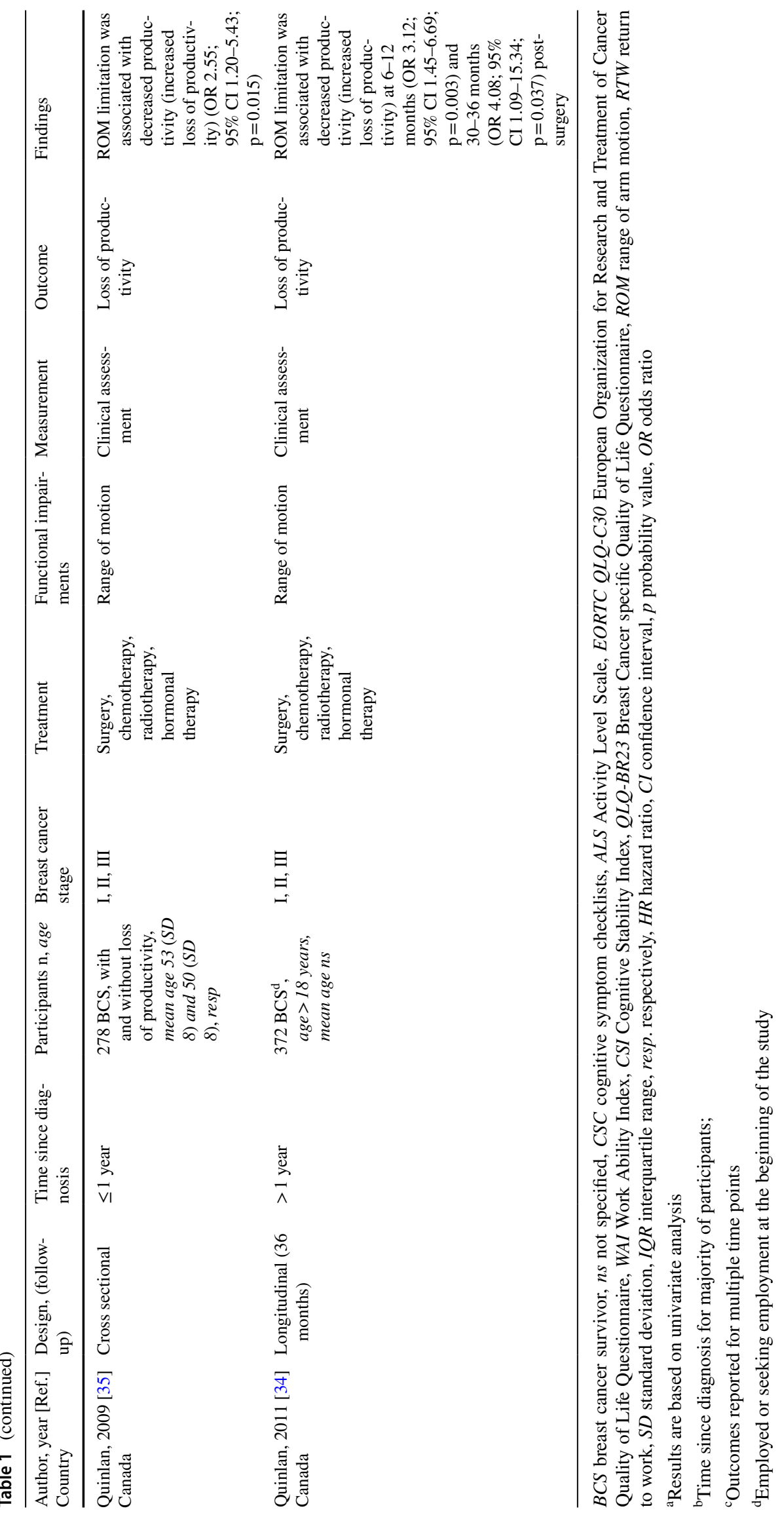




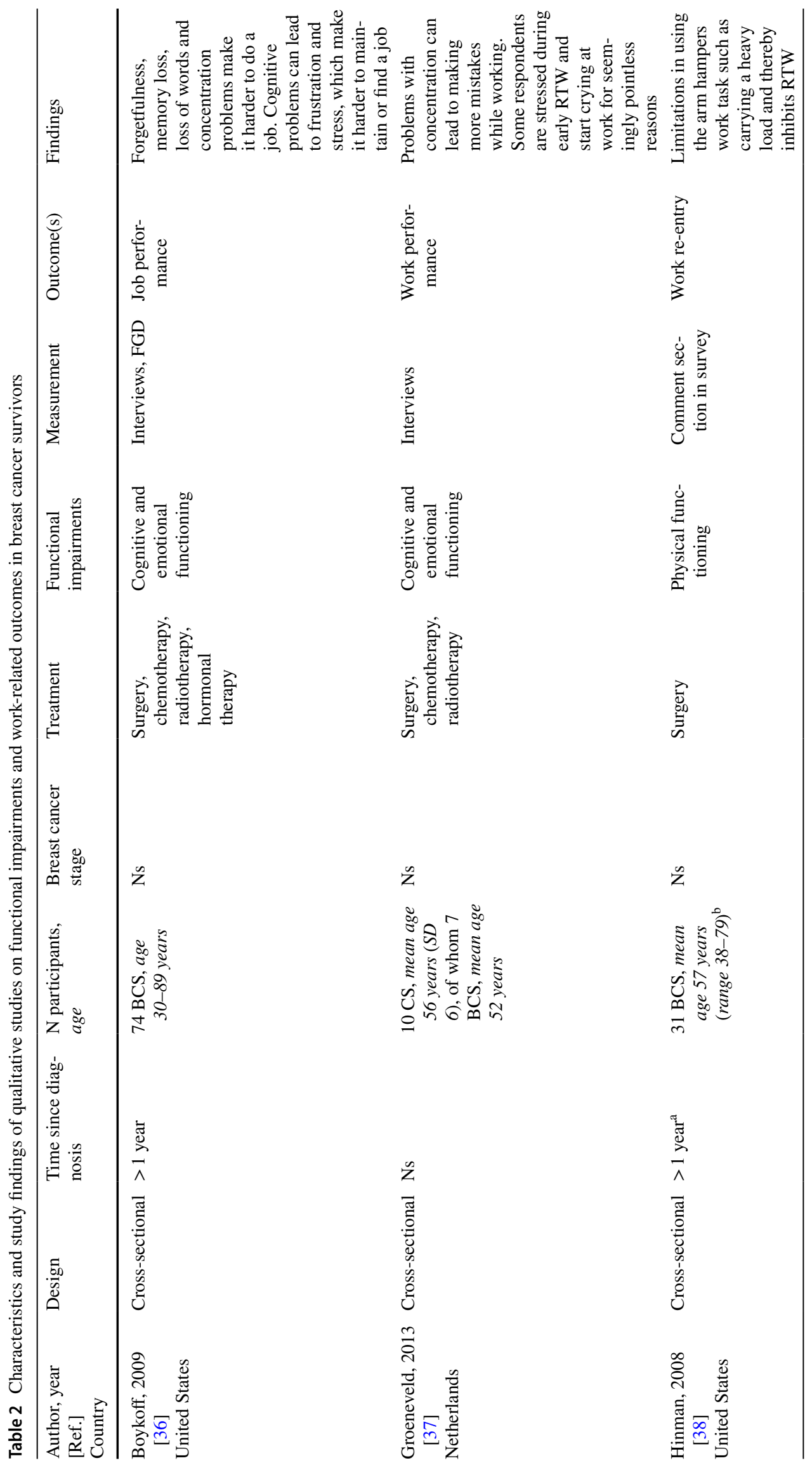




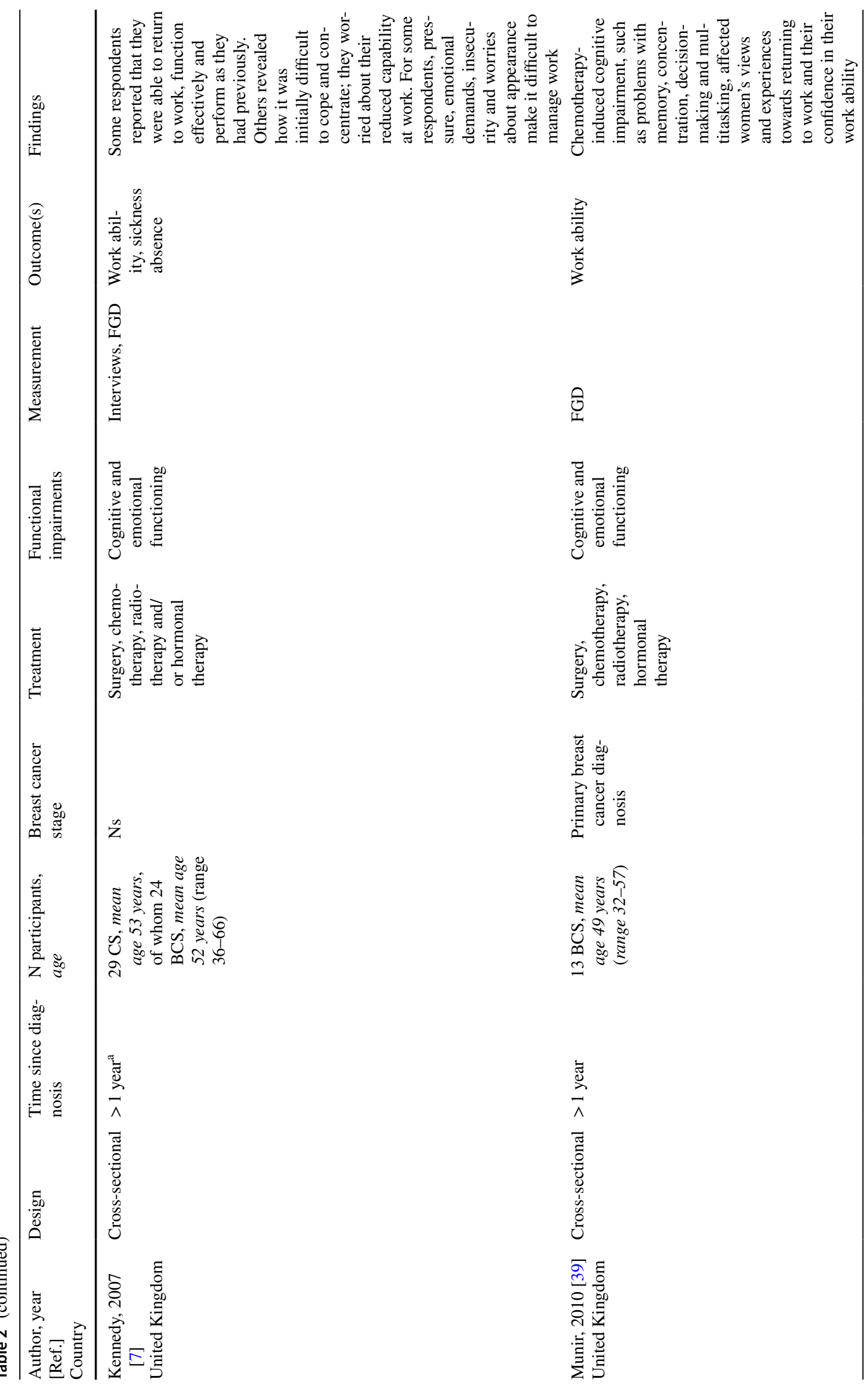




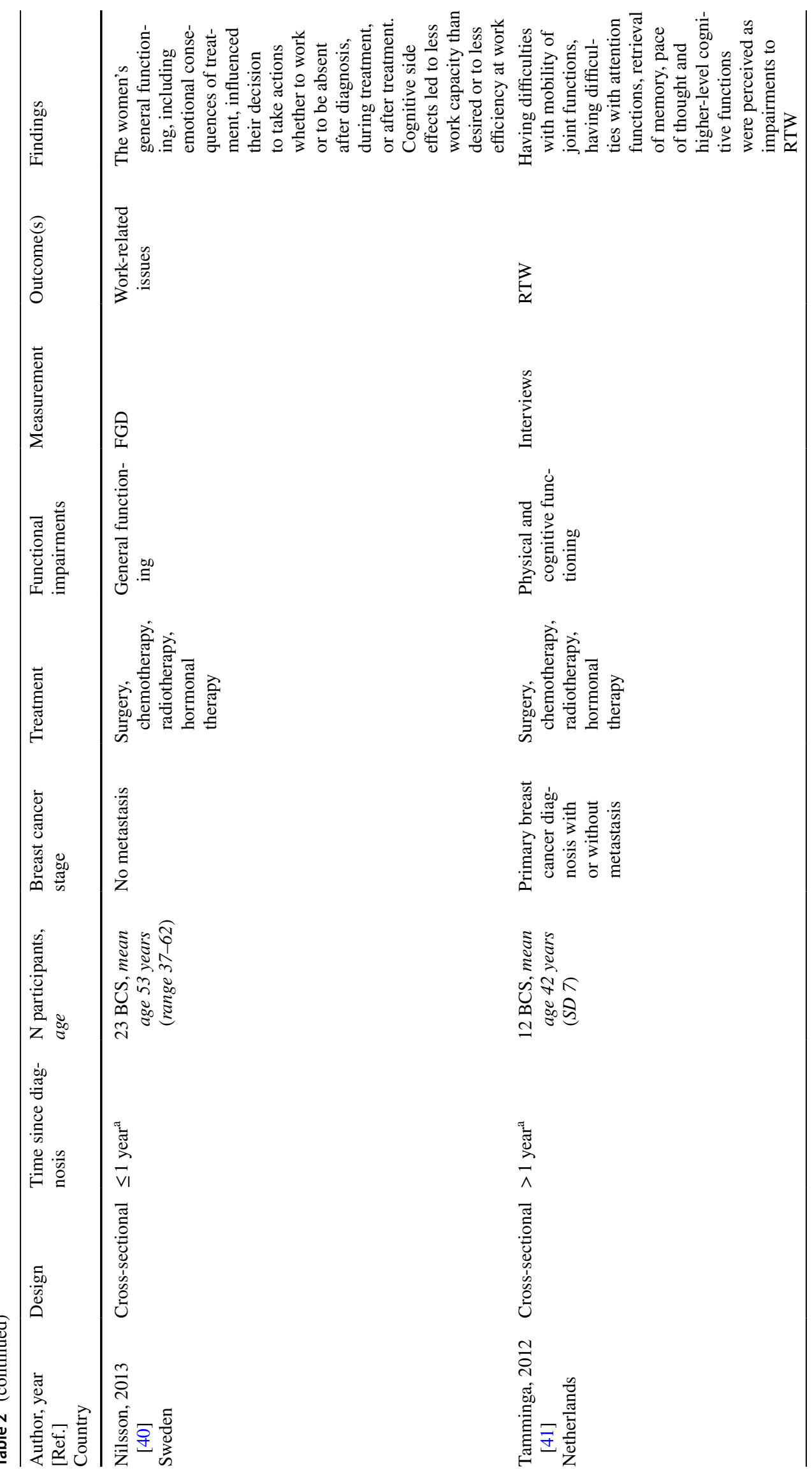



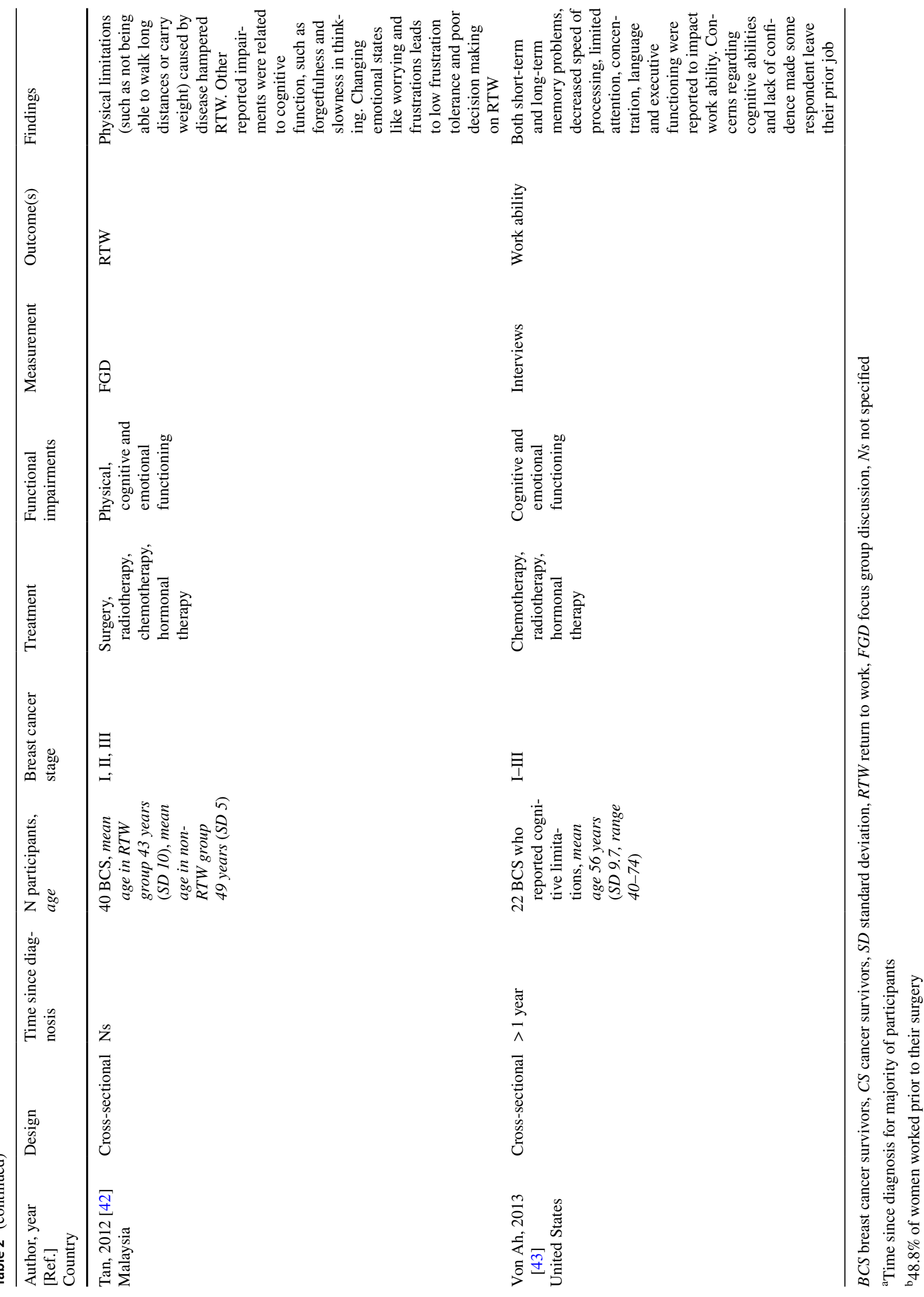
[27]. Better role functioning was associated with a slightly increased chance to RTW [31], but not with the duration until RTW [28].

\section{Physical Functioning}

Generally, problems with physical functioning were associated with negative work outcomes. For instance, a higher proportion of breast cancer survivors with physical disabilities was not employed or had left the workforce at 12 and 18 months after diagnosis [33]. In addition, reduced physical work ability led to more than a twofold increase in work changes and less overall work ability [29]. More specifically, problems with shoulder functioning were reported to impact RTW and work ability after RTW. For example, limited range of motion was associated with a loss of productivity [35], which was still apparent 2.5-3 years after surgery [34]. Furthermore, shoulder functioning impairment prolonged sick leave duration until partial RTW, but not until full RTW [25]. Interestingly, general physical functioning was not associated with duration until RTW [28] or working hours [33].

\section{Cognitive Functioning}

Cognitive functioning was evaluated by means of performance-based test [26, 31] and self-reported measures [26, 28-30, 33]. Breast cancer survivors with low scores on neuropsychological performance tests did not differ from those who had high scores with regard to RTW [31] and work output [26]. Findings from self-reported measures were somewhat inconsistent. Breast cancer survivors with a higher level of subjective cognitive impairment were more likely to be unemployed, to have left the workforce [33], or have lower work output [26]. However, other findings indicated that subjective cognitive functioning was not associated with work-related outcomes, such as duration until RTW [28], work productivity [30], working hours [33], and work changes [29].

\section{Social and Emotional Functioning}

Less commonly investigated in relation to work-related outcomes were the domains of social and emotional functioning. Better social functioning was associated with higher RTW rates [31], but not with the duration until RTW [28]. With respect to emotional functioning, none of the findings showed significant associations with work-related outcomes in breast cancer survivors $[28,31,32]$.

\section{Qualitative Studies}

A total of nine studies reported qualitative results regarding one or more domains of functioning [7, 36-43]. One study described general functioning [40], three studies described physical functioning [38, 41, 42], seven studies described cognitive functioning [7, 36, 37, 39-41, 43], and seven studies described emotional functioning [7, 36, 37, 39, $40,42,43]$. Study participants were asked about the various domains through interviews [7, 36, 37, 41, 43], focus group discussions [7, 36, 39, 40, 42] or a comment section in a survey [38]. The domains of functioning were mainly described in relation to RTW [38-42], and work ability [7, $36,37,39,40,43]$.

\section{General Functioning}

Impaired functioning in general was described as the driver of decisions on going to work or taking sick leave immediately following diagnosis, during treatment and in the phase thereafter [40].

\section{Physical Functioning}

Problems with mobility and executing physical tasks, such as carrying and walking, were reported to hamper RTW [38, $41,42]$. This became clear from studies in which women related their physical impairments to specific tasks at work. For example, a participant in the study by Tan et al. [42] explained: "I am physically tired; I was not able to walk long distance, and not able to monitor work because I noticed I was breathless during walking or going up a flight of stair." In some cases, the decision not to resume a job is made by others than the breast cancer survivor, which was explained by one woman in a study, in which women were interviewed who had undergone a mastectomy: "I was the assistant manager of a convenience store and did a lot of heavy lifting and stacking. They would not take me back after the surgery" [38].

\section{Cognitive Functioning}

The findings showed that work-related outcomes were greatly impacted by cognitive impairments, including problems with concentration, attention, memory, pace of thought, multitasking, executive functioning, speed of processing and decision-making. These impairments were perceived to be related to the process of returning to work [39, 41, 42] as well as to problems with work ability by occupationally active breast cancer survivors [7, 36, 37, 39, 40, 43]. Impairments in cognitive functioning commonly became apparent beyond RTW, as was explained by a 51-year old senior receptionist in a study on chemotherapy-induced cognitive 
problems: "It was when I went back to work I noticed, I felt as though I'd had a lobotomy" [39]. Especially when numerous cognitive functions are required for completing a job task, this was described as leading to problems when working: "It makes my job a lot harder, because as a teacher you have to do everything all at once. So, when I leave at the end of the day, I am spent, when before I was energetic. And it's not a physical spent; it is a mental spent that I didn't used to have" [36]. Fortunately, the negative impact of cognitive impairment was also reported to diminish as time passed by, which was discussed by women, who had undergone breast surgery, in a focus group study: "I had been on sick leave for a month when I realized that I could not concentrate, but now I work just as before" [40].

\section{Emotional Functioning}

Breast cancer diagnosis and treatment were reported to affect emotional functioning, which influenced choices on RTW. For instance, returning to work was described as a source of stress, at times leading women to tear up [7, 37]. Furthermore, low-spiritedness, fears, worries, frustrations and insecurity about appearances made it challenging for some breast cancer survivors to resume employment [7, 40, 42]. One woman elaborated on her insecurity at work after getting a breast prosthesis: "I had to lean down to do anything on the bottom, lower shelf or even for bags to pack them, I was like this [covered her chest] all the time, holding it together... every minute of my working day you're thinking of it" [7]. Cognitive impairment resulting from treatment was frequently cited as an additional reason for insecurity and frustration [36, 39, 43]. These problems in turn were explained to change the experience of work as it used to be, which for instance made an office manager retire early: "With this memory thing, I was very frustrated at work and so I thought that I can't go on like this. It was a chore now going to work than a joy. I just assessed the situation and said that it's not worth it" [36].

\section{Discussion}

In this systematic review, we explored the association between functional impairments and work-related outcomes in breast cancer survivors. The findings show that overall, better functional status was related to more favourable workrelated outcomes. Impairments in physical functioning were consistently described as negatively impacting RTW and work ability in both quantitative and qualitative studies. With regards to cognitive functioning, the findings were inconsistent across studies. Studies measuring cognitive functioning with neuro-psychological performance-based tests found no association with work-related outcomes, whereas the results of studies using self-reported measures of cognitive function were ambiguous. In qualitative studies, however, cognitive impairments were frequently reported as hampering RTW and diminishing work ability. Social functioning was less commonly investigated and findings differed across workrelated outcomes. Emotional functioning was not associated with work-related outcomes in quantitative studies, while in qualitative studies, feelings such as stress, fear, worries, frustration, insecurity and low-spiritedness were described as influencing decisions on RTW.

\section{Interpretation of Findings}

The findings show that physical functioning was univocally related to RTW and work ability, whereas findings for other domains of functioning were not as straightforward. This might partly be because in scientific literature, the concept of work disability is primarily focused on physical aspects of functioning, and to a lesser extent on cognitive, social and emotional aspects [44]. This might be reflective of what happens in practice. Indeed, occupational health physicians evaluating disability in cancer survivors have reported to rely mainly on a biomedical approach, while subjective complaints of psychosocial functioning, which are harder to assess, take a less prominent position [45].

As previously reported for cancer survivors in general [46], our review confirmed a difference between selfreported and performance-based measures of cognitive functioning. Studies have shown little correlation between these measures in cancer survivors [47, 48]. It has been suggested that breast cancer survivors might perform better at tests because they are aware of their limitations and try to overcome them in a test setting [26]. Furthermore, it is possible that performance-based tests are not sensitive in picking up impairments in cognitive functioning which are required for specific tasks at work. Hence, occupational health professionals should be cautious in generalising test results to cognitive functioning needed at work. Instead, to facilitate favourable work-related outcomes, it seems expedient to interpret cognitive functioning in light of each individual's daily work activities.

Our review showed that, in various studies, breast cancer survivors reported emotional functioning to negatively impact work participation. According to a study among Japanese and Dutch participants, emotional responses elicited by breast cancer are stronger than those in individuals with other chronic diseases, such as asthma and diabetes [49, 50]. Furthermore, other findings have indicated that suppressing emotional responses to breast cancer might be related to emotional impairment [51]. Research suggests that social support and the ability to disclose feelings are pivotal in coping with emotional issues caused by breast cancer [51, 52]. However, evidence shows that there is a high unmet need 
for support with these issues among breast cancer survivors [53]. Taken together, these findings allude to the importance of providing the information and support to help women cope with their condition and lessen emotional struggle [51, 52]. Subsequently, this might improve overall functioning and facilitate work participation.

Interestingly, in qualitative studies participants consistently reported that functional impairments negatively affected RTW and work ability, while findings were divergent across quantitative studies. This might be attributable to how breast cancer survivors perceive their health condition, and the difference in manifestation of these perceptions in qualitative and quantitative studies. Firstly, impairments can subjectively be experienced as debilitating by breast cancer survivors, even though they might be too subtle to objectively determine. A possible explanation for this difference is that individuals commonly overestimate their predisease level of functioning and consequently set unrealistic rehabilitation goals [54]. Secondly, according to Leventhal, individuals form a set of beliefs about their disease and the consequences thereof, based on their personal experiences, medical knowledge, and environmental input [55], which may mediate or exacerbate outcomes in the period following illness. As shown by a recent review, illness perceptions of breast cancer survivors indeed appear to be linked to various important health and behavioural outcomes [56]. For instance, having a strong belief that diagnosis and treatment lead to serious symptoms or problems with activities of daily life has been associated with poorer mental and physical health [57]. Likewise, work-related outcomes may be affected by illness perception as well. This is illustrated by a review which reports that believing one's illness is longlasting and has serious consequences for health and daily life is more often seen in non-working individuals than in those with more favourable illness perceptions [58].

\section{Strengths and Limitations}

The main strength of this review is that, rather than discussing determinants in general of RTW of breast cancer survivors, we focussed specifically on functional impairments in relation to work outcomes. By distilling a more homogenous set of findings, our review provides a unique perspective which can provide practical guidance to those in the field of occupational medicine. Specifically, our findings give direction to how occupational health professionals can support breast cancer survivors in returning to work and retain them on the work floor. Another strength is that, by including both quantitative and qualitative studies, we revealed the potential importance of perceptions regarding work participation after breast cancer.

An important limitation to the study is that findings are difficult to compare between countries, due to major differences in social security systems [59]. For instance, in countries such as Canada and the Netherlands it is possible to work under therapeutic conditions, that is, to resume parttime work and gradually increase work activities and working hours over the course of multiple years while receiving partial disability benefits $[60,61]$. In other countries, however, disability benefits are only granted in case of more severe work incapacity, though at the same time, employees are at risk of termination of their employment contract [59]. As a result, RTW cannot be interpreted similarly across countries. In correspondence to this, the heterogeneity in measurement of work-related outcomes and social security systems in which these outcomes are embedded prevents the possibility of pooling quantitative results and conducting a meta-analysis, which would provide stronger evidence.

\section{Implications for Practice and Research}

Occupational health professionals should be aware that experienced problems in functioning that influence work participation might not be objectively measurable. That is, illness perceptions of breast cancer survivors play an essential role in RTW, and research has shown a discrepancy between the illness perceptions of employees and occupational health physicians [62]. Further, breast cancer survivors should receive an overview of potential side effects of treatment and possible consequences to their functional status, specifically in relation to future work resumption. By increasing medical knowledge and addressing unfavourable illness perceptions, occupational health professionals can facilitate a smoother RTW process. Additionally, helping breast cancer survivors to revise unrealistic expectations might contribute to less emotional problems such as distress and frustration [54].

Our findings put forward important directions for future research. First, we found a wide variety of work-related outcomes, which implies the need for a common framework to assess work participation. Second, there is a lack of literature on important work-related outcomes after cancer, such as changes in work activities and working hours. Research on these outcomes is warranted, since they may be desirable end points if work resumption at the pre-disease level is an unrealistic goal. Finally, the importance of perceptions regarding work participation after breast cancer should be further investigated in research.

\section{Conclusions}

Our findings indicate that functional impairments can severely hamper work participation in breast cancer survivors. Notwithstanding, there might be important opportunities for occupational health professionals to enhance RTW and work retention in breast cancer survivors. Specifically, 
opportunities exist in adequately addressing illness perceptions and work expectations. Ongoing research is needed to aid occupational health professionals in providing effective vocational guidance and improve work-related outcomes in breast cancer survivors.

Acknowledgements We would like to thank the Dutch Cancer Society for funding the fellowship of dr. Saskia Duijts (VU2013-5866), which enables her to conduct research in the field 'cancer and work', including this study. This work was initiated as part of a wider research project on 'breast cancer and work', which was supported with a subsidy of the UWV (Employee Insurance Agency).

\section{Compliance with Ethical Standards}

Conflict of interest Rimke Bijker, Saskia F.A. Duijts, Sherzel N. Smith, Renée de Wildt-Liesveld, Johannes R. Anema and Barbara J. Regeer declare that they have no conflict of interest.
Research Involving Animal and Human Rights No animal or human studies were carried out by the authors for this article.

Open Access This article is distributed under the terms of the Creative Commons Attribution 4.0 International License (http://creativeco mmons.org/licenses/by/4.0/), which permits unrestricted use, distribution, and reproduction in any medium, provided you give appropriate credit to the original author(s) and the source, provide a link to the Creative Commons license, and indicate if changes were made.

\section{Appendix 1: PubMed Search Strategy}

\begin{tabular}{|c|c|c|}
\hline Search & Query & Items found \\
\hline \#5 & Search (\#4) Filters: Publication date from 2000/01/01 & 150 \\
\hline \#4 & $\# 1$ AND \#2 AND \#3 & 194 \\
\hline \#3 & $\begin{array}{l}\text { "Recovery of Function“[Mesh] OR "Disability Evaluation“[Mesh] OR "Sickness } \\
\text { Impact Profile“[Mesh] OR "Physical Fitness“[Mesh] OR "Movement"[Mesh] } \\
\text { OR impairment*[tiab] OR disabilit*[tiab] OR } \\
\text { Capabilit*[tiab] OR capacit*[tiab] OR impair*[tiab] OR function*[tiab] OR } \\
\text { dysfunction*[tiab] OR limitation*[tiab] OR restriction*[tiab] OR physical } \\
\text { fitness[tiab] OR movement*[tiab] OR mobilit*[tiab] OR EORTC QLQ[tiab] OR } \\
\text { Functional Assessment of Cancer Therapy[tiab] OR SF-36[tiab] OR functional } \\
\text { abilit*[tiab] OR functional capa*[tiab] }\end{array}$ & $4,518,304$ \\
\hline$\# 2$ & $\begin{array}{l}\text { "Convalescence“[Mesh] OR "Absenteeism“[Mesh] OR "Sick Leave"[Mesh] } \\
\text { OR "Return to Work“[Mesh] OR "Work Performance"[Mesh] OR } \\
\text { "Unemployment"[Mesh] OR "Retirement"[Mesh] OR "Work Capacity } \\
\text { Evaluation"[Mesh] OR ("Efficiency“[Mesh] AND (work*[tiab] OR job*[tiab])) } \\
\text { OR convalescen*[tiab] OR absenteeism[tiab] OR work absence*[tiab] OR } \\
\text { disability absence*[tiab] OR sickness absence*[tiab] OR sick day*[tiab] } \\
\text { OR illness day*[tiab] OR work day loss*[tiab] OR work time loss*[tiab] } \\
\text { OR medical leave*[tiab] OR sick leave*[tiab] OR sickness leave*[tiab] OR } \\
\text { disability leave*[tiab] OR presenteeism[tiab] OR sickness presence[tiab] } \\
\text { OR return-to-work[tiab] OR back- to-work[tiab] OR reintegration[tiab] OR } \\
\text { reemployment[tiab] OR job reentry[tiab] OR work productivit*[tiab] OR work } \\
\text { function*[tiab] OR work participation[tiab] OR work performance*[tiab] OR } \\
\text { performance at work[tiab] OR employment status[tiab] OR work status[tiab] } \\
\text { OR unemployment[tiab] OR unemployed[tiab] OR work abilit*[tiab] OR } \\
\text { workability[tiab] OR work disabilit*[tiab] OR work inabilit*[tiab] OR work } \\
\text { capacit*[tiab] OR work incapacity[tiab] OR work capabilit*[tiab] OR work } \\
\text { incapabilit*[tiab] OR work inhibition*[tiab] OR work function*[tiab] OR } \\
\text { job function*[tiab] OR work participation[tiab] OR work performanc*[tiab] } \\
\text { OR job performanc*[tiab] OR vocational performanc*[tiab] OR perfor- } \\
\text { mance at work[tiab] OR work productivit*[tiab] OR work efficien*[tiab] OR } \\
\text { job efficien*[tiab] OR work retention[tiab] OR work sustainability[tiab] OR } \\
\text { retirement*[tiab] OR working hour*[tiab] OR work hour*[tiab] OR work } \\
\text { task*[tiab] OR working task*[tiab] OR task at work[tiab] OR tasks at work[tiab] } \\
\text { OR job task*[tiab] }\end{array}$ & 93,643 \\
\hline \#1 & $\begin{array}{l}\text { "Breast Neoplasms"[Mesh] OR (("Breast"[Mesh] OR breast[tiab]) AND } \\
\text { ("Neoplasms"[Mesh] OR neoplas*[tiab] OR cancer*[tiab] OR carcin*[tiab] OR } \\
\text { tumour*[tiab] OR tumor*[tiab] OR metasta*[tiab] OR malig*[tiab])) }\end{array}$ & 319,566 \\
\hline
\end{tabular}




\section{Appendix 2: Embase Search Strategy}

\begin{tabular}{|c|c|c|}
\hline Search & Query & Items found \\
\hline \#5 & $\begin{array}{l}\text { \#4 AND (2000:py OR 2001:py OR 2002:py OR 2003:py OR 2004:py OR } \\
\text { 2005:py OR 2006:py OR 2007:py OR 2008:py OR 2009:py OR 2010:py } \\
\text { OR 2011:py OR 2012:py OR 2013:py OR 2014:py OR 2015:py OR } \\
\text { 2016:py) }\end{array}$ & 364 \\
\hline \#4 & \#1 AND \#2 AND \#3 & 402 \\
\hline \#3 & $\begin{array}{l}\text { ‘disability’/exp OR ‘functional status assessment'/exp OR ‘Sickness Impact } \\
\text { Profile'/exp OR 'functional status'/exp OR ‘fitness'/exp OR ‘move- } \\
\text { ment (physiology)'/exp OR impairment*:ab,ti OR disabilit*:ab,ti OR } \\
\text { capabilit*:ab,ti OR capacit*:ab,ti OR impair*:ab,ti OR function*:ab,ti OR } \\
\text { dysfunction*:ab,ti OR limitation*:ab,ti OR restriction*:ab,ti OR 'physi- } \\
\text { cal fitness':ab,ti OR movement*:ab,ti OR mobilit*:ab,ti OR 'EORTC } \\
\text { QLQ':ab,ti OR 'Functional Assessment of Cancer Therapy’:ab,ti OR 'SF- } \\
\text { 36':ab,ti OR 'functional abilit*':ab,ti OR 'functional capa*':ab,ti }\end{array}$ & 5.354 .001 \\
\hline \#2 & 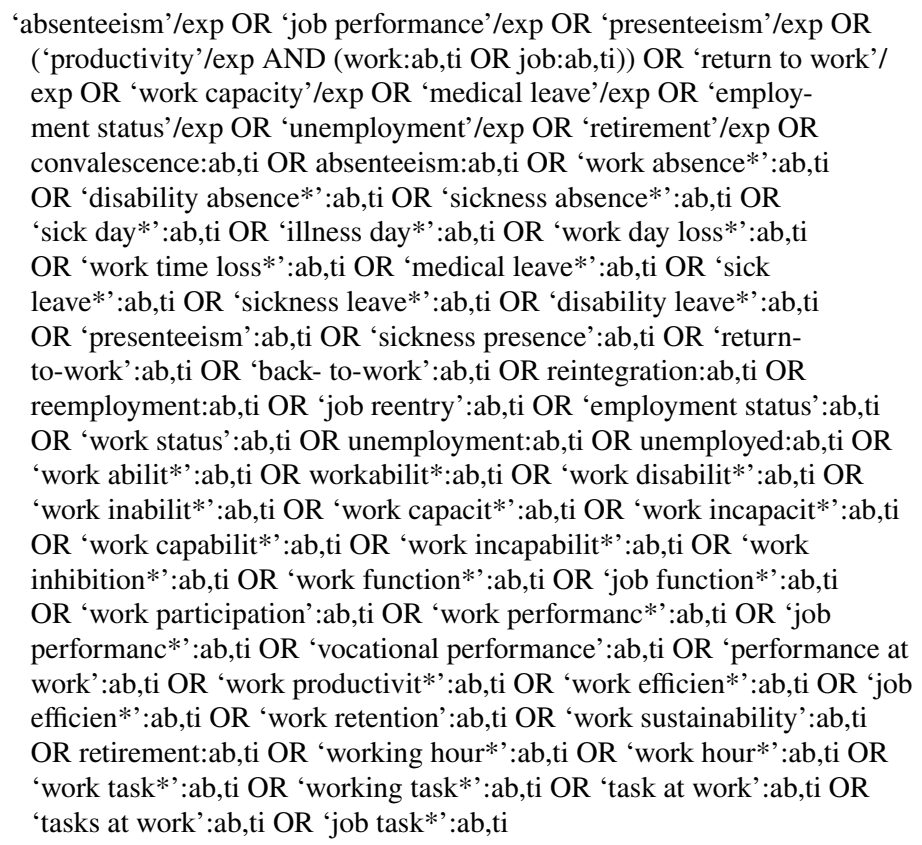 & 125.134 \\
\hline \#1 & $\begin{array}{l}\text { 'breast cancer'/exp OR 'breast cancer':ab,ti OR ('breast'/exp OR } \\
\text { breast:ab,ti AND ('neoplasm'/exp OR 'neoplasm':ab,ti OR cancer*:ab,ti } \\
\text { OR neoplasm*:ab,ti OR carcin*:ab,ti OR tumor*:ab,ti OR tumour*:ab,ti } \\
\text { OR metastas*:ab,ti)) }\end{array}$ & 485.200 \\
\hline
\end{tabular}

\section{Appendix 3: Psyclnfo Search Strategy}

\begin{tabular}{|c|c|c|}
\hline Search & Query & Items found \\
\hline \#5 & Limiters_Publication Year: 2000-2016 & 152 \\
\hline \#4 & S1 AND S2 AND S3 & 165 \\
\hline \#3 & $\begin{array}{l}\text { MM “Disability Evaluation" OR MM "Physical Fitness" OR TI impairment* OR AB impairment* OR TI } \\
\text { disabilit* OR AB disabilit* OR TI capabilit* OR AB capabilit* OR TI capacit* OR AB capacit* OR TI } \\
\text { impair* OR AB impair* OR TI function* OR AB function* OR TI dysfunction* OR AB dysfunction* } \\
\text { OR TI limitation* OR AB limitation* OR TI restriction* OR AB restriction* OR TI "physical fitness" } \\
\text { OR AB "physical fitness" OR TI movement* OR AB movement* OR TI mobilit* OR AB mobilit* OR } \\
\text { TI "EORTC QLQ" OR AB "EORTC QLQ" OR TI "Functional Assessment of Cancer Therapy" OR AB } \\
\text { "Functional Assessment of Cancer Therapy" OR TI "SF-36" OR AB "SF-36" OR TI "functional abilit*” } \\
\text { OR AB "functional abilit*" OR TI "functional capa*" OR AB "functional capa*" }\end{array}$ & 940,188 \\
\hline
\end{tabular}




\begin{tabular}{|c|c|c|}
\hline Search & Query & Items found \\
\hline \#2 & 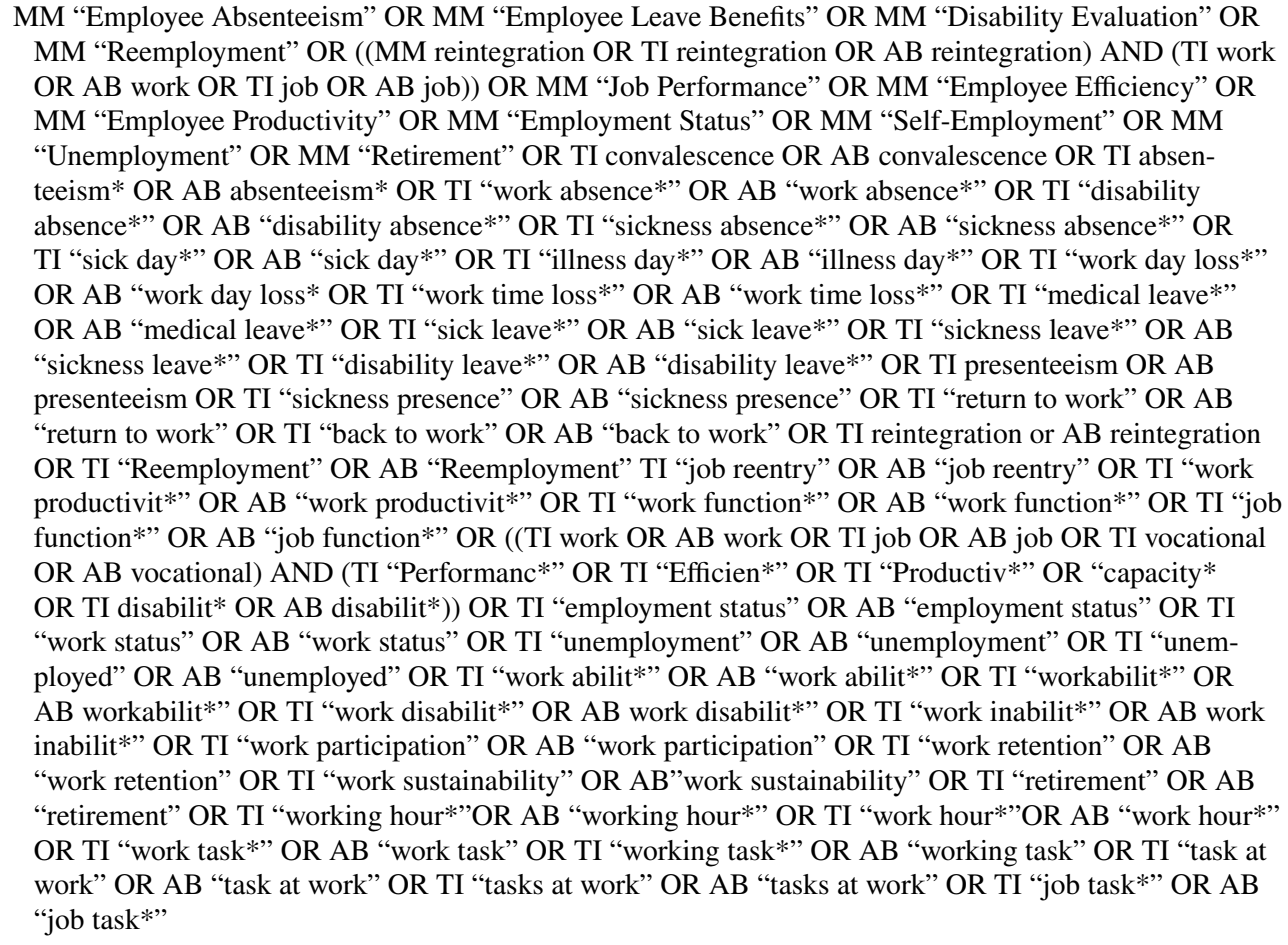 & 135,480 \\
\hline$\# 1$ & 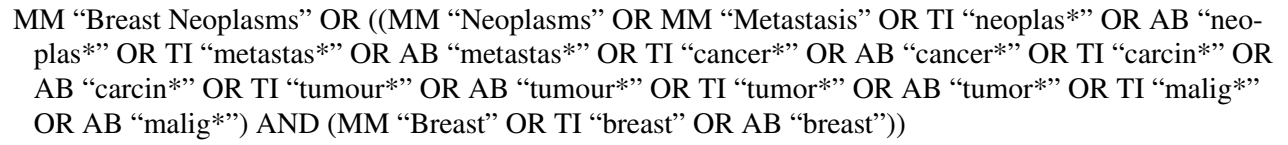 & 11,055 \\
\hline
\end{tabular}

\section{Appendix 4: CINAHL Search Strategy}

\begin{tabular}{|c|c|c|}
\hline Search & Query & Items found \\
\hline \#5 & Limiters_Published Date: 20000101-20151231 & 202 \\
\hline \#4 & S1 AND S2 AND S3 & 230 \\
\hline \#3 & 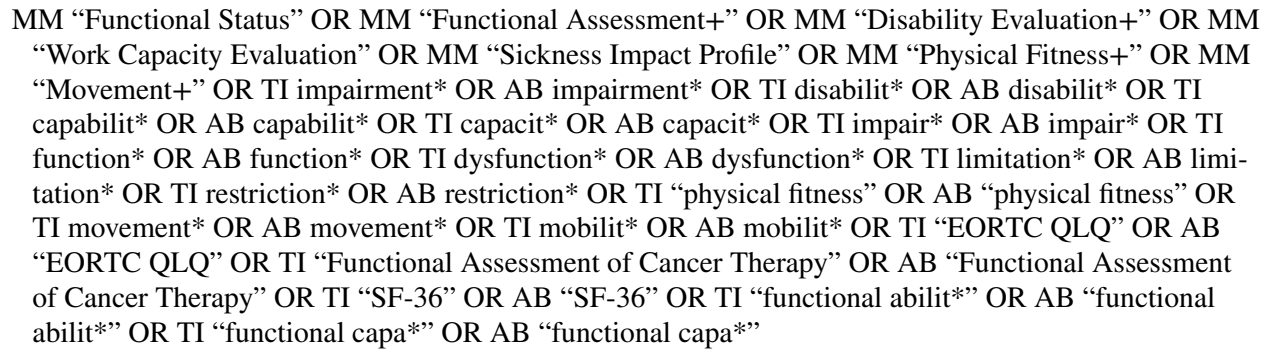 & 344,183 \\
\hline
\end{tabular}




\begin{tabular}{|c|c|c|}
\hline Search & Query & Items found \\
\hline$\# 2$ & 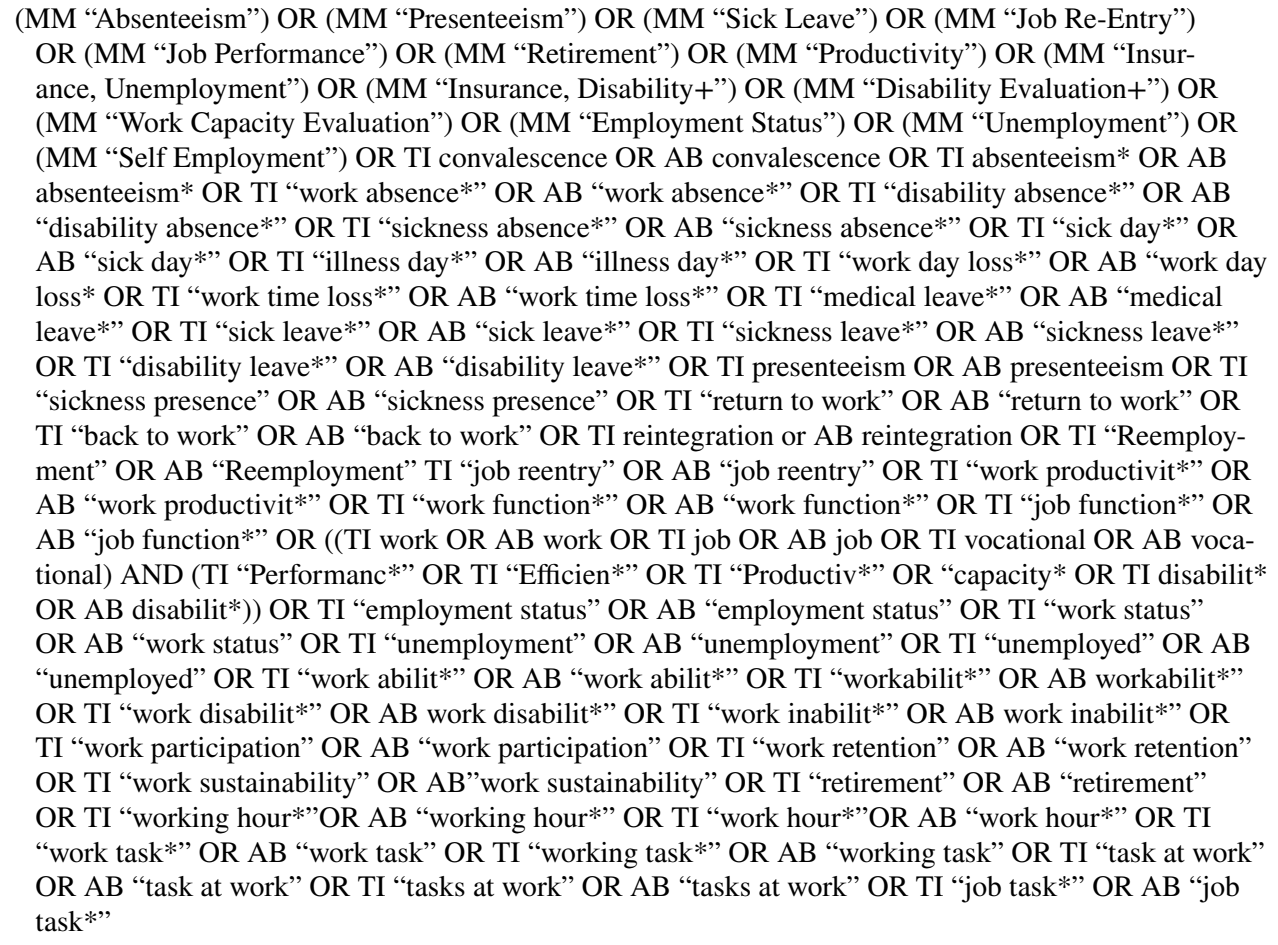 & 69,142 \\
\hline$\# 1$ & $\begin{array}{l}\text { (MM “Breast Neoplasms+”) OR ((MM “Breast+" OR TI “breast” OR AB “breast”) AND (MM } \\
\text { "Neoplasms+” OR TI “neoplas*” OR AB “neoplas*” OR TI “metastas*” OR AB “metastas*” OR TI } \\
\text { "cancer*” OR AB “cancer*” OR TI "carcin*” OR AB “carcin*” OR TI “tumour*” OR AB “tumour*” } \\
\text { OR TI “tumor*” OR AB “tumor*” OR TI “malig*” OR AB “malig*”)) }\end{array}$ & 38,310 \\
\hline
\end{tabular}

\section{Appendix 5: Cochrane Library Search Strategy}

\begin{tabular}{llr}
\hline ID & Search & Hits \\
\hline$\# 1$ & MeSH descriptor: [Breast Neoplasms] explode all trees & 9746 \\
$\# 2$ & MeSH descriptor: [Breast] explode all trees & 668 \\
$\# 3$ & breast:ti,ab,kw & 26,635 \\
$\# 4$ & $\# 2$ or \#3 & 26,646 \\
$\# 5$ & MeSH descriptor: [Neoplasms] explode all trees & 58,274 \\
$\# 6$ & neoplas* or cancer* or carcin* or tumour* or tumor* or metasta* or malig*:ti,ab,kw (Word & 11,301 \\
& $\quad$ variations have been searched) & 21,704 \\
$\# 7$ & $\# 5$ or \#6 & 132 \\
$\# 8$ & $\# 4$ and \#7 & 481 \\
$\# 9$ & $\# 1$ or \#8 & 2850 \\
$\# 10$ & MeSH descriptor: [Convalescence] explode all trees & 485 \\
$\# 11$ & MeSH descriptor: [Absenteeism] explode all trees & 21,704 \\
$\# 12$ & MeSH descriptor: [Disability Evaluation] explode all trees & 0 \\
$\# 13$ & MeSH descriptor: [Sick Leave] explode all trees & 0 \\
$\# 14$ & MeSH descriptor: [Return to Work] explode all trees & 200 \\
$\# 15$ & MeSH descriptor: [Work Performance] explode all trees & 43 \\
$\# 16$ & MeSH descriptor: [Work Capacity Evaluation] explode all trees & 92 \\
$\# 17$ & MeSH descriptor: [Retirement] explode all trees & 3813 \\
$\# 18$ & $\# 10$ or \#11 or \#12 or \#13 or \#14 or \#15 or \#16 or \#17 & \\
\hline
\end{tabular}




\begin{tabular}{|c|c|c|}
\hline ID & Search & Hits \\
\hline \#19 & $\begin{array}{l}\text { convalescen* or absenteeism or work absence* or disability absence* or sickness absence* } \\
\text { or sick day* or illness day* or work day loss* or work time loss* or medical leave* or sick } \\
\text { leave* or sickness leave* or disability leave* or presenteeism or sickness presence or return- } \\
\text { to-work or back- to-work or reintegration or reemployment or job reentry or work produc- } \\
\text { tivit* or work function* or work participation or work performance* or performance at work } \\
\text { or employment status or work status or unemployment or unemployed or work abilit* or } \\
\text { workability or work disabilit* or work inabilit* or work capacit* or work incapacity or work } \\
\text { capabilit* or work incapabilit* or work inhibition* or work function* or job function* or } \\
\text { work participation or work performanc* or job performanc* or vocational performanc* or } \\
\text { performance at work or work productivit* or work efficien* or job efficien* or work reten- } \\
\text { tion or work sustainability or retirement* or working hour* or work hour* or work task* or } \\
\text { working task* or task at work or tasks at work or job task*:ti,ab,kw (Word variations have } \\
\text { been searched) }\end{array}$ & 28,828 \\
\hline \#20 & MeSH descriptor: [Efficiency] explode all trees & 321 \\
\hline \#21 & work* or job*:ti,ab,kw (Word variations have been searched) & 35,272 \\
\hline \#22 & $\# 20$ and \#21 & 166 \\
\hline \#23 & $\# 18$ or \#19 or \#22 & 31,022 \\
\hline \#24 & $\# 9$ and \#23 & 289 \\
\hline \#25 & \#24 Publication Year from 2005 & 213 \\
\hline \#26 & MeSH descriptor: [Recovery of Function] explode all trees & 3841 \\
\hline \#27 & MeSH descriptor: [Disability Evaluation] explode all trees & 2850 \\
\hline \#28 & MeSH descriptor: [Sickness Impact Profile] explode all trees & 520 \\
\hline \#29 & MeSH descriptor: [Physical Fitness] explode all trees & 2444 \\
\hline \#30 & MeSH descriptor: [Movement] explode all trees & 23,319 \\
\hline \#31 & $\begin{array}{l}\text { impairment* or disabilit* or capabilit* or capacit* or impair* or function* or dysfunction* } \\
\text { or limitation* or restriction* or physical fitness or movement* or mobilit* or EORTC QLQ } \\
\text { or Functional Assessment of Cancer Therapy or SF-36 or functional abilit* or functional } \\
\text { capa*:ti,ab,kw (Word variations have been searched) }\end{array}$ & 195,331 \\
\hline \#32 & $\# 26$ or \#27 or \#28 or \#29 or \#30 or \#31 & 206,145 \\
\hline \#34 & $\# 9$ and \#23 and \#32 & 136 \\
\hline \#33 & $\# 9$ and \#23 and \#32 Publication Year from 2000 & 120 \\
\hline
\end{tabular}

\section{References}

1. Fitzmaurice C, Dicker D, Pain A, Hamavid H, Moradi-Lakeh $\mathrm{M}$, MacIntyre MF, et al. Global burden of disease cancer collaboration. The global burden of cancer 2013. JAMA Oncol. 2015;1(4):505-527.

2. Chaker L, Falla A, van der Lee SJ, Muka T, Imo D, Jaspers L, et al. The global impact of non-communicable diseases on macroeconomic productivity: a systematic review. Eur J Epidemiol. 2015;30(5):357-395.

3. Lindbohm ML, Taskila T, Kuosma E, Hietanen P, Carlsen K, Gudbergsson $\mathrm{S}$, et al. Work ability of survivors of breast, prostate, and testicular cancer in Nordic countries: a NOCWO study. J Cancer Surviv. 2011;6(1):72-81.

4. Paalman $\mathrm{CH}$, van Leeuwen FE, Aaronson NK, de Boer AG, van de Poll-Franse L, Oldenburg HS, et al. Employment and social benefits up to 10 years after breast cancer diagnosis: a populationbased study. Br J Cancer. 2016;114(1):81-87.

5. Global Burden of Disease Study 2015 (GBD 2015). Results. United States: Institute for Health Metrics and Evaluation (IHME). http://ghdx.healthdata.org/gbd-results-tool (2016). Accessed 7 Jan 2017.

6. Blinder VS, Murphy MM, Vahdat LT, Gold HT, de Melo-Martin I, Hayes MK, et al. Employment after a breast cancer diagnosis: a qualitative study of ethnically diverse urban women. J Community Health. 2012;37(4):763-772.

7. Kennedy F, Haslam C, Munir F, Pryce J. Returning to work following cancer: a qualitative exploratory study into the experience of returning to work following cancer. Eur J Cancer Care. 2007;16(1):17-25.

8. Mackenzie CR. 'It is hard for mums to put themselves first': how mothers diagnosed with breast cancer manage the sociological boundaries between paid work, family and caring for the self. Soc Sci Med. 2014;117:96-106.

9. Raque-Bogdan TL, Hoffman MA, Ginter AC, Piontkowski $\mathrm{S}$, Schexnayder K, White R. The work life and career development of young breast cancer survivors. J Couns Psychol. 2015;62(4):655-669.

10. Lundh MH, Lampic C, Nordin K, Ahlgren J, Bergkvist L, Lambe $\mathrm{M}$, et al. Changes in health-related quality of life by occupational status among women diagnosed with breast cancer-a populationbased cohort study. Psychooncology. 2013;22(10):2321-2331.

11. Timperi AW, Ergas IJ, Rehkopf DH, Roh JM, Kwan ML, Kushi LH. Employment status and quality of life in recently diagnosed breast cancer survivors. Psychooncology. 2013;22(6):1411-1420.

12. Mehnert A. Employment and work-related issues in cancer survivors. Crit Rev Oncol Hematol. 2011;77(2):109-130.

13. van Muijen P, Weevers NL, Snels IA, Duijts SF, Bruinvels DJ, Schellart AJ, et al. Predictors of return to work and employment 
in cancer survivors: a systematic review. Eur J Cancer Care. 2013;22(2):144-160.

14. Feuerstein M, Todd BL, Moskowitz MC, Bruns GL, Stoler MR, Nassif T, et al. Work in cancer survivors: a model for practice and research. J Cancer Surviv. 2010;4(4):415-437.

15. DiSipio T, Rye $S$, Newman B, Hayes $S$. Incidence of unilateral arm lymphoedema after breast cancer: a systematic review and meta-analysis. Lancet Oncol. 2013;14(6):500-515.

16. Taghian NR, Miller CL, Jammallo LS, O'Toole J, Skolny MN. Lymphedema following breast cancer treatment and impact on quality of life: a review. Crit Rev Oncol Hematol. 2014;92(3):227-234.

17. Stewart A, Bielajew C, Collins B, Parkinson M, Tomiak E. A meta-analysis of the neuropsychological effects of adjuvant chemotherapy treatment in women treated for breast cancer. Clin Neuropsychol. 2006;20(1):76-89.

18. Taillibert S, Le Rhun E, Chamberlain MC. Chemotherapy-related neurotoxicity. Curr Neurol Neurosci Rep. 2016;16(9):81. doi: https://doi.org/10.1007/s11910-016-0686-x.

19. de Boer AG, Taskila TK, Tamminga SJ, Feuerstein M, FringsDresen MH, Verbeek JH. Interventions to enhance returnto-work for cancer patients. Cochrane Database Syst Rev. 2015;25:CD007569. doi:https://doi.org/10.1002/14651858. CD007569.pub3.

20. Rijksoverheid. Wet Verbetering Poortwachter. The Netherlands: Rijksoverheid. http://wetten.overheid.nl/BWBR0013063/geldi gheidsdatum_04-02-2016 (2016). Accessed 4 Feb 2016.

21. NVAB. Blauwdruk kanker en werk [Blueprint cancer and work]. Utrecht: NVAB; 2009.

22. Cloeren M, Gean C, Kesler D, Green-McKenzie J, Taylor M, Upfal M, et al. American College of Occupational and Environmental Medicine's Occupational and Environmental Medicine Competencies-2014: ACOEM OEM Competencies Task Force. J Occup Environ Med. 2014;56(5):e21-e40.

23. Critical appraisal skills programme. CASP Checklists. United Kingdom: CASP UK. http://www.casp-uk.net/ (2013). Accessed 13 May 2016.

24. STROBE statement. Checklist of items that should be included in reports of cross-sectional studies. Switzerland: University of Bern. http://www.strobe-statement.org/index.php?id=strobe-home (2007). Accessed 13 May 2016

25. Balak F, Roelen CA, Koopmans PC, Ten Berge EE, Groothoff JW. Return to work after early-stage breast cancer: a cohort study into the effects of treatment and cancer-related symptoms. J Occup Rehabil. 2008;18(3):267-272.

26. Calvio L, Peugeot M, Bruns GL, Todd BL, Feuerstein M. Measures of cognitive function and work in occupationally active breast cancer survivors. J Occup Environ Med. 2010;52(2):219-227.

27. Cleeland CS, Mayer M, Dreyer NA, Yim YM, Yu E, Su Z, et al. Impact of symptom burden on work-related abilities in patients with locally recurrent or metastatic breast cancer: Results from a substudy of the VIRGO observational cohort study. Breast. 2014;23(6):763-769.

28. Cooper AF, Hankins M, Rixon L, Eaton E, Grunfeld EA. Distinct work-related, clinical and psychological factors predict return to work following treatment in four different cancer types. Psychooncology. 2013;22(3):659-667.

29. Gudbergsson SB, Fosså SD, Dahl AA, NOCWO. A study of work changes due to cancer in tumor-free primary-treated cancer patients. A NOCWO study. Support Care Cancer. 2008;16(10):1163-1171.

30. Hansen JA, Feuerstein M, Calvio LC, Olsen CH. Breast cancer survivors at work. J Occup Environ Med. 2008;50(7):777-784.

31. Hedayati E, Johnsson A, Alinaghizadeh H, Schedin A, Nyman $\mathrm{H}$, Albertsson M. Cognitive, psychosocial, somatic and treatment factors predicting return to work after breast cancer treatment. Scand J Caring Sci. 2013;27(2):380-387.

32. Lundh MH, Lampic C, Nordin K, Ahlgren J, Bergkvist L, Lambe $\mathrm{M}$, et al. Sickness absence and disability pension following breast cancer-a population-based matched cohort study. Breast. 2014;23(6):844-851.

33. Oberst K, Bradley CJ, Gardiner JC, Schenk M, Given CW. Work task disability in employed breast and prostate cancer patients. J Cancer Surviv. 2010;4(4):322-330.

34. Quinlan E, Maclean R, Hack T, Tatemichi S, Towers A, Kwan W, et al. Breast cancer survivorship and work disability. J Disabil Policy Stud. 2011;22(1):18-27.

35. Quinlan E, Thomas-MacLean R, Hack T, Kwan W, Miedema B, Tatemichi S, et al. The impact of breast cancer among Canadian women: disability and productivity. Work. 2009;34(3):285-296.

36. Boykoff N, Moieni M, Subramanian SK. Confronting chemobrain: an in-depth look at survivors' reports of impact on work, social networks, and health care response. J Cancer Surviv. 2009;3(4):223-232.

37. Groeneveld IF, de Boer AG, Frings-Dresen MH. Physical exercise and return to work: cancer survivors' experiences. J Cancer Surviv. 2013;7(2):237-246.

38. Hinman MR. Factors influencing work disability for women who have undergone mastectomy. Women Health. 2001;34(2):45-60.

39. Munir F, Burrows J, Yarker J, Kalawsky K, Bains M. Women's perceptions of chemotherapy-induced cognitive side affects on work ability: a focus group study. J Clin Nurs. 2010;19(9-10):1362-1370.

40. Nilsson MI, Olsson M, Wennman-Larsen A, Petersson LM, Alexanderson K. Women's reflections and actions regarding working after breast cancer surgery - a focus group study. Psychooncology. 2013;22(7):1639-1644.

41. Tamminga SJ, de Boer AG, Verbeek JH, Frings-Dresen MH. Breast cancer survivors' views of factors that influence the returnto-work process - a qualitative study. Scand J Work Environ Health. 2012;38(2):144-154.

42. Tan FL, Loh SY, Su TT, Veloo VW, Ng L. Return to work in multi-ethnic breast cancer survivors - a qualitative inquiry. Asian Pac J Cancer Prev. 2012;13(11):5791-5797.

43. Von Ah D, Habermann B, Carpenter JS, Schneider BL. Impact of perceived cognitive impairment in breast cancer survivors. Eur J Oncol Nurs. 2013;17(2):236-241.

44. Lederer V, Loisel P, Rivard M, Champagne F. Exploring the diversity of conceptualizations of work (dis)ability: a scoping review of published definitions. J Occup Rehabil. 2014;24(2):242-267.

45. van Muijen P, Duijts SF, Kornet-van der Aa DA, van der Beek AJ, Anema JR. Work disability assessment of cancer survivors: insurance physicians' perspectives. Occup Med. 2015;65(7):558-563.

46. Duijts SF, van der Beek AJ, Boelhouwer IG, Schagen SB. Cancer-related cognitive impairment and patients' ability to work: a current perspective. Curr Opin Support Palliat Care. 2017;11(1):19-23.

47. Poppelreuter M, Weis J, Külz AK, Tucha O, Lange KW, Bartsch HH. Cognitive dysfunction and subjective complaints of cancer patients. Eur J Cancer. 2004;40(1):43-49.

48. Shilling V, Jenkins V. Self-reported cognitive problems in women receiving adjuvant therapy for breast cancer. Eur J Oncol Nurs. 2007;11(1):6-15.

49. Broadbent E, Petrie KJ, Main J, Weinman J. The brief illness perception questionnaire. J Psychosom Res. 2006;60(6):631-637.

50. Kaptein AA, Yamaoka K, Snoei L, van der Kloot WA, Inoue $\mathrm{K}$, Tabei T, et al. Illness perceptions and quality of life in Japanese and Dutch women with breast cancer. J Psychosoc Oncol. 2013;31(1):83-102.

51. Tamagawa R, Giese-Davis J, Speca M, Doll R, Stephen J, Carlson LE. Trait mindfulness, repression, suppression, and self-reported 
mood and stress symptoms among women with breast cancer. J Clin Psychol. 2013;69(3):264-277.

52. Mehnert A, Koch U. Psychological comorbidity and healthrelated quality of life and its association with awareness, utilization, and need for psychosocial support in a cancer register-based sample of long-term breast cancer survivors. J Psychosom Res. 2008;64(4):383-391.

53. Fiszer C, Dolbeault S, Sultan S, Brédart A. Prevalence, intensity, and predictors of the supportive care needs of women diagnosed with breast cancer: a systematic review. Psychooncology. 2014;23(4):361-374.

54. Leventhal H, Phillips LA, Burns E. The Common-Sense Model of Self-Regulation (CSM): a dynamic framework for understanding illness self-management. J Behav Med. 2016;39(6):935-946.

55. Leventhal H, Leventhal EA, Breland JY. Cognitive science speaks to the "common-sense" of chronic illness management. Ann Behav Med. 2011;41(2):152-163.

56. Kaptein AA, Schoones JW, Fischer MJ, Thong MS, Kroep JR, van der Hoeven KJ. Illness perceptions in women with breast cancer-a systematic literature review. Curr Breast Cancer Rep. 2015;7(3):117-126.
57. Rozema H, Völlink T, Lechner L. The role of illness representations in coping and health of patients treated for breast cancer. Psychooncology. 2009;18(8):849-857.

58. Hoving JL, van der Meer M, Volkova AY, Frings-Dresen MH. Illness perceptions and work participation: a systematic review. Int Arch Occup Environ Health. 2010;83(6):595-605.

59. Anema JR, Schellart AJ, Cassidy JD, Loisel P, Veerman TJ, van der Beek AJ. Can cross country differences in return-to-work after chronic occupational back pain be explained? An exploratory analysis on disability policies in a six country cohort study. J Occup Rehabil. 2009;19(4):419-426.

60. Krause N, Dasinger LK, Neuhauser F. Modified work and return to work: a review of the literature. J Occup Rehabil. 1998;8(2):113-139.

61. Van Egmond MP, Duijts SF, Jonker MA, van der Beek AJ, Anema JR. Effectiveness of a tailored return to work program for cancer survivors with job loss: results of a randomized controlled trial. Acta Oncol. 2016;55(9-10):1210-1219.

62. Giri P, Poole J, Nightingale P, Robertson A. Perceptions of illness and their impact on sickness absence. Occup Med. 2009;59(8):550-555. 